\title{
EFFEGTS OF DIMORPHOLAMINE ON BLOOD PRESSURE
}

\author{
AKIRA SAKUMA*, HITOSHI KATO** AND YOSHIAKI SAJI*** \\ Department of Pharmacology, Faculty of Medicine, University of Tokyo, Bunkyo-ku, Tokyo
}

Received for publication May 27, 1965

Since the introduction as a respiratory stimulant $(1,2)$ dimorpholamine $(1064 \mathrm{Th}$, Théraptique, Atmurin, N, $\mathrm{N}^{\prime}$-dibutyl-N,N'-dicarboxymorpholine-ethylenediamine:, has been enjoying its clinical use as a potent analeptic.

Cardiovascular effects of dimorpholamine had been extensively studied by Kanda and his coworkers (3-5) chiefly in rabbits. They concluded that the pressor effect of dimorpholamine might be the sum of direct vascular effect of non-adrenergic nature and central effect increasing sympathetic vasoconstrictor tone. On the other hand, Luduena and Long (6) were led to a conclusion that the pressor effect in dogs might be due mainly to a direct non-nicotinic excito-secretory action on the adrenal medulla.

The central effects of dimorpholamine were investigated in the head perfusion preparation of dogs and the adrenergic nature of the non-central pressor action was established in this department. Recent advances in concept and technique concerning cardiovascular pharmacology stimulated us to reinvestigate the mechanism involved in the effects of dimorpholamine.

\section{METHODS AND MATERIALS}

In all series of experiments adult mongrel dogs unselected as to sex were employed, unless otherwise stated. In some experiments, cats, rats and rabbits were also used. The results of experiments were considered on at least 6 replicates.

Whole animal: The dogs were anesthetized with pentobarbital sodium, $30 \mathrm{mg} / \mathrm{kg}$ intravenously or intraperitoneally, and small doses were supplemented when necessary. The animal was fixed in a supine or side position and a tracheal cannula was inserted. Blood pressure was recorded from the femoral artery by an ordinary double-arm mercury manometer, and respiratory movement by an accordion-type pneumograph connected to a tambour. Drugs were administered with saline flush via the cannula inserted into

\section{佐久間 昭・加藤 仁・佐治 美昭}

Present address : * Department of Pharmacology, Institute for Cardiovascular Diseases, Faculty of Medicine, Tokyo Medical \& Dental University; ** Department of Chemical Pharmacology, Faculty of Pharmaceutical Sciences, University of Tokyo ; *** Research Laboratories, Takeda Pharmaceutical Co., Ltd.

A part of the present study was submitted by H.K. to University of Tokyo in partial fulfillment of the requirements for the degree of Master of Pharmaceutical Sciences in 1957. The paper was presented at the 19th Annual Meeting of Japanese Pharmaceutical Sciences in Tokyo, 1964. 
the external jugular vein. In some experiments with smaller species, blood pressure was recorded by the aid of a high-pressure transducer.

Spinal animal (7): The animal was anesthetized with thiopental sodium, $25 \mathrm{mg} / \mathrm{kg}$. The trachea and esophagus were cut and retoroflexed, and the ventral arch of the first vertebra was exposed. After removal of the ventral arch, the dura mater was cut, the bilateral vagosympathetic nerve trunks were severed and the bilateral common carotid arteries were ligated. Under artificial respiration, the spinal cord was transected at the level of the occipito-atloid joint, and the brain was destroyed with a blunt probe. The experiment was started 1 hour after the spinal transection. When the movement of the nictitating membrane was to be recorded in cats, the spinal preparation was prepared without ligation of the common carotid arteries and destruction of the basal portion of the brain.

Adrenalectomy: Through incisions made on the flank areas of the anesthetized animal, the bilateral adrenal glands were separated from the surrounding tissues and the blood vessels connected to the glands were doubly ligated and cut to remove the glands. In some animals, the adrenals were extirpated after partial evisceration.

Hindquarter perfusion (autocirculation, 8): The anesthetized animal was placed on a board and incision was made on its left flank area. The aorta was exposed retroperitoneally, ligated at about the level of L3 and doubly cannulated. A pulsatile, constantoutput pump was placed between the divided aorta for supplying blood to the hindquarters. The systemic blood pressure was recorded from the proximal end of the aorta with a double-arm mercury manometer and the perfusion pressure from the distal end of the aorta with a single-arm manometer. The animal received heparin sodium 5 $\mathrm{mg} / \mathrm{kg}$ previous to the initiation of perfusion. The bilateral sympathetic chains were severed at the level of L5-6 when denervation was desired.

Head perfusion (cross-circulation, e.g , 9): The donor dog was stunned by electroshock applied to the forehead or anesthetized with pentobarbital sodium and heparinized at the beginning of perfusion. The recipient dog was anesthetized with pentobarbital sodium. The circulatory system of the animal was transversely divided at the occipito-atloid level by surgical procedures, the spinal cord and vagosympathetic nerve trunks being left intact. The blood vessels outside as well as inside the vertebral canal were severed with an electroknife or ligated as completely as possible. An arterial cannula was inserted cranially into each common carotid artery and a venous cannula into each transverse sinus of the recipient dog. The head circulation of the recipient was supported by a pulsatile, constant-output pump placed between the recipient and the donor. The systemic blood pressure was recorded from the femoral artery of the recipient and the perfusion pressure from the circuit at the entrance to the common carotid arteries with ordinary manometers.

Agents: The agents used in this study were as follows: 6890-A, McN-A-343, P-286, SY 14, acetylcholine chloride (ACh), atropine sulfate, cocaine hydrochloride, Dibenamine hydrochloride, dichloroanalog of isoproterenol hydrochloride (DCI), dimorpholamine 
(Théraptique, Atmurin), dimethylphenylpiperazinium bromide (DMPP), l-epinephrine hydrochloride (Adrenalin), hexamethonium bromide (Methobromin), nethalide hydrochloride, nicotine bitartrate, $d l$-norepinephrine hydrochloride (Noradrenalin), phenoxybenzamine hydrochloride (Dibenzyline) and tripelennamine hydrochloride (Pyribenzamine). The dose of the agents was expressed in terms of salt, when applicable, with exceptions of epinephrine and norepinephrine being expressed as free base.

\section{RESULTS}

Whole animal: One to $4 \mathrm{mg} / \mathrm{kg}$ of dimorpholamine given intravenously prcduced a sharp rise in blood pressure lasting about 5 to 10 minutes in dogs, less markedly in cats, and weakly in rats and rabbits.

The pattern of pressor response in dogs roughly simulated that of 1 to $5 \mu \mathrm{g} / \mathrm{kg}$ of epinephrine or norepinephrine. The size of pressor effect of dimorpholamine was dose dependent in certain range of dose. The pressor effect, however, was not sharp when lower doses were employed, and was associated with generalized convulsions when higher doses, about $5 \mathrm{mg} / \mathrm{kg}$ or more, were rapidly injected into the vein. At the peak of hypertensive response to dimorpholamine a slowing of the heart beat or arrhythmia usually appeared. The pressor response was accompanied by a slight slowing of the heart beat, and sometimes preceded by a sharp transient fall in blood pressure with slow heart rate. Bilateral vagotomy or pretreatment with atropine in a dose of 0.5 to $2 \mathrm{mg} / \mathrm{kg}$ almost completely abolished the preceding hypotensive response and the marked arrhythmia.

Pretreatment of the animal with 10 to $20 \mathrm{mg} / \mathrm{kg}$ of hexamethonium usually abolished the hypotension and marked slowing of the heart beat as did atropine. It did not reduce the hypertensive response to dimorpholamine but potentiated the response, differentiating dimorpholamine from such nicotinic agents as ACh (after atropine), nicotine and DMPP. The effect of dimorpholamine was not significantly modified by P-286 in a cumulative dose of 4 to $8 \mathrm{mg} / \mathrm{kg}$.

Atropine, $1 \mathrm{mg} / \mathrm{kg}$, which completely abolished the depressor as well as the pressor responses to 50 to $100 \mu \mathrm{g} / \mathrm{kg}$ of McN-A-343 failed to negate the hypertensive effect of dimorpholamine and slightly reduced the pressor effect.

Pretreatment of the animal with an alpha adrenergic blocking agent, SY 14 in 5 to $10 \mathrm{mg} / \mathrm{kg}$, Dibenamine in 10 to $20 \mathrm{mg} / \mathrm{kg}$ or phenoxybenzamine in 5 to $10 \mathrm{mg} / \mathrm{kg}$, reversed the pressor effect of dimorpholamine when the blood pressure was high, or highly reduced the pressure rise when the blood pressure was considerably low. On the other hand, a beta adrenergic blocker, DCI or nethalide in dose of 2 to $5 \mathrm{mg} / \mathrm{kg}$ slightly potentiated the hypertensive effect of dimorpholamine. These findings indicated dimorpholamine resembling epinephrine rather than norepinephrine in cardiovascular effects in dogs.

Close intraarterial injection of dimorpholamine in a total amount of 1.5 to $4.5 \mathrm{mg}$ into the vertebral or common carotid artery produced a slight rise in blood pressure, 
the latter route of administration giving a somewhat larger response.

The reversal or depression of the pressor effect due to dimorpholamine was not so evident in rats and rabbits as in dogs.

Spinal animal: In the spinal dogs and less obviously in the spinal cats, the pressor effect of dimorpholamine as observed in the whole animal was noted. The pattern of the blood pressure change due to dimorpholamine in $3 \mathrm{mg} / \mathrm{kg}$ was similar to that of epinephrine in dose of 2 to $5 \mu \mathrm{g} / \mathrm{kg}$. With higher doses of dimorpholamine the animal developed gross twitches of extremities. Alpha adrenergic blockers almost completely abolished the pressor response to dimorpholamine as well as those to the equihypertensive doses of epinephrine and nicotine.

Hexamethonium, atropine or the combination did not obviously alter the effect of dimorpholamine. Cocaine in dose of 0.5 to $1 \mathrm{mg} / \mathrm{kg}$ injected 5 to 15 minutes before administration of dimorpholamine potentiated the hypertensive effect, but the potentiation was of much less degree than that observed with catecholamines. Cocaine sometimes depressed the response to dimorpholamine conversely, whereas it always exaggerated the pressor effect of catecholamines.

In the spinal cats whose superior cervical ganglia were removed, intravenous injection of dimorpholamine caused an intense contraction of the nictitating membrane when a sharp rise in blood pressure was produced. Essentially the same response was noted when the ganglia were intact. It took more than 30 seconds to induce the contraction after injection, while the equipotent dose of epinephrine required less than 20 seconds for the response of the nictitating membrane.

When introduced into the ipsilateral common carotid artery in dose of 50 to 100 $\mu \mathrm{g}$, dimorpholamine produced a minor contraction of the nictitating membrane of the cat with a delay of 15 to 20 seconds. The size of contraction was slightly smaller than that produced by $0.01 \mu \mathrm{g}$ of epinephrine injected into the same site. The delay of the contraction induced by epinephrine was about 10 seconds or less.

Adrenalectomy: Dimorpholamine in dose of 1 to $4 \mathrm{mg} / \mathrm{kg}$, which produced an epinephrine-like pressor response in intact or spinal dogs, produced a small pressor response in dogs whose bilateral adrenals had been removed. This small hypertensive response was often preceded by a biphasic hypotension with marked slowing of heart beat. Single or combined use of hexamethonium, phenoxybenzamine and 6890-A did not significantly depress the pressor response in the adrenalectomized animals.

It is very suggestive to compare the pressor response of dimorpholamine and that of DMPP in the adrenalectomized animals (Fig. 1A, B, C). In case of DMPP, only the initial components of blood pressure change were observed after adrenalectomy, and these evanescent responses were almost completely abolished by hexamethonium in dose of 10 to $20 \mathrm{mg} / \mathrm{kg}$, while in case of dimorpholamine the pressor component, but not the depressor component observed after adrenalectomy was resistant to the dose of hexamethonium abolishing the classical nicotinic action. Furthermore, the vascular response to dimorpholamine was discriminated from those of McN-A-343 and epinephrine in the 


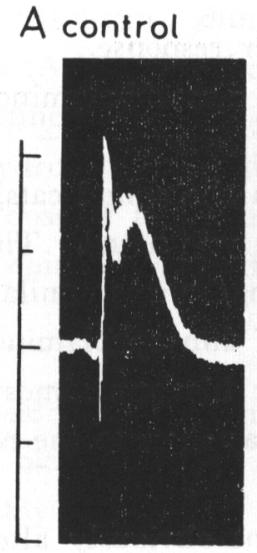

DMPP 40 $\mathrm{ug}$

\section{B Adr X}

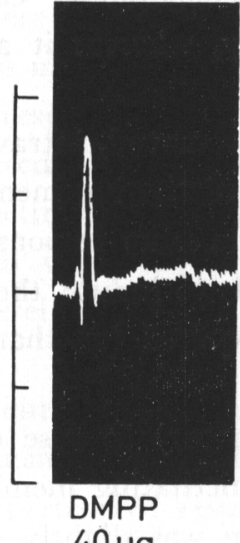

$40 \mathrm{ug}$

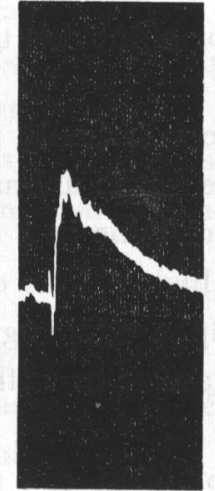

Dimor

3mg

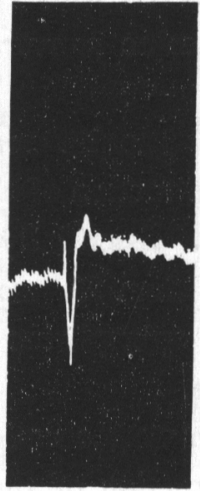

Dimor

$3 \mathrm{mg}$

C AdrX, C6 $20 \mathrm{mg} / \mathrm{kg}$ iv

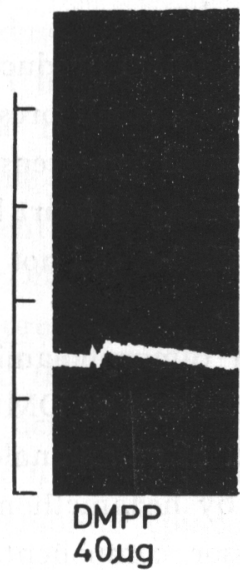

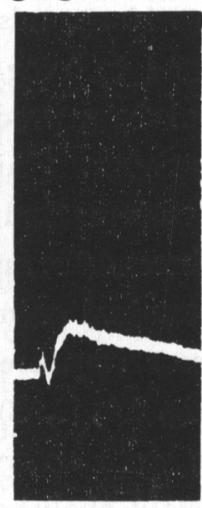

Dimor

$3 \mathrm{mg}$

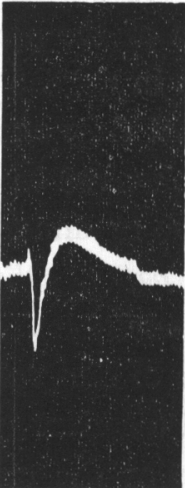

$\mathrm{McN}-\mathrm{A}$

50 ug

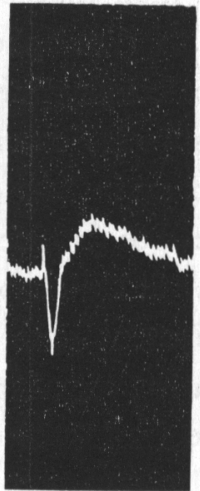

$\mathrm{McN}-\mathrm{A}$

$50 \mu \mathrm{g}$

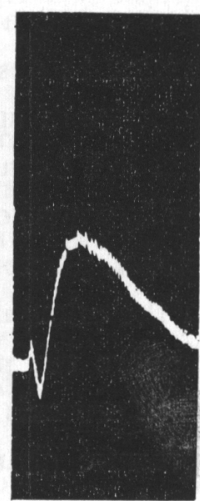

$\mathrm{McN}-\mathrm{A}$ $50 \mu \mathrm{g}$

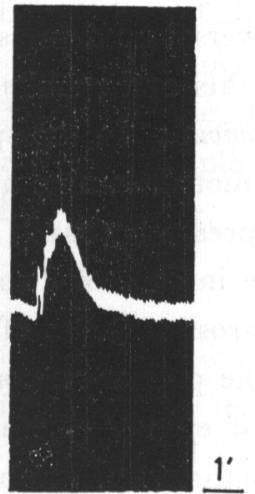

Epi

$2 \mu \mathrm{gg} / \mathrm{kg}$ iv
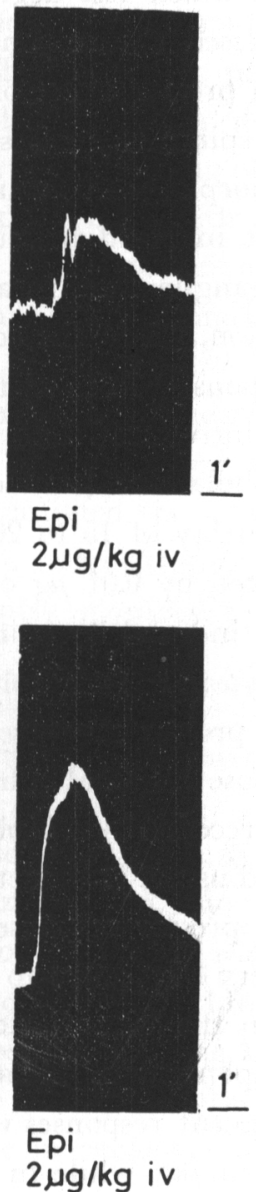

FIG. 1. Comparison of 4 pressor agents. Dimethylphenylpiperazinium (DMPP), dimorpholamine (Dimor), McN-A-343 (McN-A) and epinephrine (Epi) were given intravenously; all doses in weight $/ \mathrm{kg}$. A (control) : responses in the dog under pentobarbital anesthesia. B (AdrX) : modified responses by adrenalectomy. $\mathrm{C}$ (AdrX, $\mathrm{C}_{6} 20 \mathrm{mg} / \mathrm{kg}$ iv) : pressor effects after administration of hexamethonium following adrenalectomy. 
adrenalectomized animal.

In cats, the effect of adrenalectomy upon the pressor effect of dimorpholamine was similar to that observed in dogs, while the removal of the adrenals only slightly reduced the pressor response to dimorpholamine in rats and rabbits. The pressor effect due to dimorpholamine in the latter species was not so prominent as in dogs, and the effect remaining after adrenalectomy was rather resistant to alpha adrenergic blocker and hexamethonium.

Hindquarter perfusion: In the autocirculation preparation of hindquarters, close intraarterial injection of dimorpholamine into the perfused hindquarters in dose of 1 to 9 mg produced a small rise or a biphasic change in the perfusion pressure in most cases. The pattern of vascular response in the hindquarters to dimorpholamine seemed to be independent of dose, and sometimes varied in the same preparation. The vascular response to intraarterial injection of the agent was not consistently modified by the treatment with atropine, tripelennamine or 6890-A. In some animals under light anesthesia, intraarterial injection produced a sharp, transient fall in the perfusion pressure concomitantly with a tonic stretching of the hindlimbs.

When a small dose of dimorpholamine, 1 to $2 \mathrm{mg} / \mathrm{kg}$, was injected into the systemic circulation via the jugular vein, there observed was a small rise in the systemic blood pressure, which evoked a vasodilatation in the hindquarters connected to the trunk through the nerves. Furthermore, the reflex dilatation, which was abolished by bilateral sympathetic transection, was followed by a delayed hypertensive response which was considerable as compared with the response to the intraarterial injection of dimorpholamine.

Head perfusion: The introduction of dimorpholamine into the common carotid arteries in the recipient dog produced a slight rise in the trunk blood pressure with or without preceding slowing of the heart beat or hypotensive episode. The perfusion pressure was slightly depressed, presumably due to nonspecific effect of injection. The systemic response due to the central application of dimorpholamine was slightly reduced by denervation of the carotid sinus area in the recipient and the initial hypotension if existed was abolished by bilateral vagotomy.

When dimorpholamine was given intravenously into the trunk circulation via the femoral vein, a rise in the systemic pressure was observed similar to those produced in other types of experiments, resulting in a slight dilatation in the head vascular beds when the vagus nerve was intact.

Respiration: The effect of dimorpholamine upon respiratory movements was also observed in the present series of experiment. Dimorpholamine showed a remarkable respiratory stimulation in the anesthetized whole dogs in wide range of dose, larger than $0.6 \mathrm{mg} / \mathrm{kg}$. In some cases the pattern of respiratory response to the agent as judged by the respiratory movement recorded by a pneumograph largely resembled that of moderate dose of nicotine, viz., a transient expiratory apnea, transient hyperpnea and increased excursion with somewhat slow rhythm. The pattern and intensity of the respiratory excitation due to dimorpholamine, however, were highly dependent on the 
dose of the agent as well as on the level of anesthesia, and in some rabbits initial inspiratory arrest was observed.

The respiratory excitation was slightly modified by the carotid sinus denervation and little by administration of hexamethonium, and still observed in the vagotomized animals. In the head perfusion preparation, the drug was substantiated to possess direct central action to cause intense respiratory excitation, and in very large doses to cause generalized convulsions of clonic type. Dimorpholamine, however, seemed to exert minor stimulatory effects upon chemoreceptors in the aortic as well as in the carotid sinus regions, since the systemic administration of the agent in the head perfusion preparation produced respiratory excitation which was abolished by bilateral vagotomy and the respiratory excitation due to the head application of the agent was reduced by sinus denervation in some cases.

\section{DISCUSSION}

The effects of dimorpholamine upon the blood pressure of anesthetized dogs resembled those of epinephrine, norepinephrine, nicotine or DMPP. The pressor effect of dimorpholamine was reversed by pretreatment with one of alpha adrenergic blockers in a similar manner to "epinephrine reversal", and was potentiated by doses of hexamethonium which completely abolished the effect of nicotine. Furthermore, the pressor effect of dimorpholamine was potentiated by a beta adrenergic blocker. These findings indicate that dimorpholamine resembles epinephrine rather than norepinephrine, or nicotinic agents in the pattern of pressor effect. The nature of the pressor effect of dimorpholamine in cats seems essentially similar to that observed in dogs. In rats and rabbits, however, the pressor activity of dimorpholamine is somewhat resistant to alpha adrenergic blockers. This indication of the species difference in the response to dimorpholamine is consistent with the conclusion led by Kanda et al. (4).

Bilateral adrenalectomy considerably depressed the pressor effect of dimorpholamine as well as that of DMPP in dogs. The marked reduction in the pressor effect after adrenalectomy is best interpreted by the activity of these pressor agents to release catecholamines from the adrenal medulla directly or indirectly. The direct excito-secretory action of dimorpholamine on the adrenal medulla was evidenced by Luduene and Long (6) in the adrenolumbar vein-jugular anastomosis experiments in dogs. The present results essentially support their conclusion. The effect of adrenalectomy on the pressor effect of dimorpholamine was not clear again in rabbits and rats.

Recently Asakawa (10) found in the perfusion experiment of the cat adrenal gland that dimorpholamine increased the output of catecholamines from the gland thereby disproportionately increasing the amount of norepinephrine rather than epinephrine. This finding is not completely cope with the present result that the predominant amine released by dimorpholamine seems to be epinephrine. It is interesting that in the perfusion experiment dimorpholamine was ineffective when the gland was perfused with calcium-free perfusate as was the case in ACh. 
In the present series of experiments in dogs no differential determination of catecholamines was performed, but the experimental results with alpha adrenergic blocker suggest that considerable amount of epinephrine is released from the adrenal medulla. The release of pressor amines is also indicated by the delayed hypertensive effects in the perfused limbs in the hindquarter perfusion experiment, and by the delayed contraction of the nictitating membrane following the intravenous injection of dimorpholamine.

The initial hypotensive episode with a marked slowing of the heart following dimorpholamine is likely the result of the action upon the carotid sinus area or upon CNS, since the bilateral vagotomy almost completely abolish the hypotension and the central application of the agent in the head perfusion preparation sometimes produced a similar effect to that observed in the whole animal. The slowing of the heart beat, however, still exists after administration of hexamethonium in some cases might be difficult to explained on the basis of the direct effect of the agent upon the heart (11). Nicotine and DMPP also produced the initial hypotension but this response was not significantly affected by bilateral vagotomy but by hexamethonium.

In the dogs whose bilateral adrenals had been extirpated dimorpholamine still produced a small pressor response resistant to hexamethonium, phenoxybenzamine or 6890A. Although the central pressor effect of dimorpholamine was shown, its contribution to the pressor effect in the whole animal would be minor. Intraarterial injection of dimorpholamine into the perfused hindquarters produced a simple rise or a rise followed by a fall in the perfusion pressure. These responses were not consistently modified by certain blocking agents. It is interesting that the similar responses due to intraarterially injected DMPP tended to a rise after treatment with atropine or tripelennamine, and to a fall after guanethidine, bretylium or 6890-A (12).

Although we did not study the direct effect of dimorpholamine upon the heart, Kanda et al. (3) reported positive inotropic action in the isolated frog heart. Recently, Imai et al. (11) also observed that the agent produced a positive inotropic action in the heart-lung preparation of the $\mathrm{dog}$ and in the isolated frog heart. Interestingly they observed that dimorpholamine differed from sympathomimetic amine in the nature of direct cardiac effects.

These evidences suggest that the small pressor response to dimorpholamine observed in the adrenalectomized dog might be the sum of effects upon the heart and the vascular smooth muscles and some contribution of CNS effect.

Together with the respiratory stimulation the cardiovascular effects of dimorpholamine seemingly resemble those of DMPP, or nicotine, but are not of nicotinic nature in major parts. Dimorpholamine may be described as a non-nicotinic catecholamine releasing agent with some cardiotonic, vasoconstricting and central action, although the releasing action seems to be restricted to the adrenal medulla of dogs or cats. It might also be referred to as a non-nicotinic ganglion stimulant in a broad sense. More detailed mechanism of releasing action of dimorpholamine upon the adrenal medulla is to be studied in order to classify the action. In this connection it might be interesting to 
note that acetaldehyde is a calcium-independent catecholamine releasing agent (13) and vanillic acid diethylamide may be still another type of releasing agent (14).

\section{SUMMARY}

Dimorpholamine in 1 to $4 \mathrm{mg} / \mathrm{kg}$ produced an epinephrine-like pressor effect in dogs anesthetized with pentobarbital, the response being reversed by pretreatment with an alpha adrenergic blocker. The pressor effect was often preceded by a transient hypotension with marked slowing of the heart beat which disappeared after bilateral vagotomy or administration of hexamethonium.

The major part of the pressor effect disappeared following bilateral adrenalectomy, and was resistant to hexamethonium. The minor part seemed to be composed of direct vascular, cardiotonic and central actions.

Dimorpholamine might be referred to as a catecholamine releaser and/or a nonnicotinic ganglion stimulant in a broad sense. This nature was evidenced in the experiments with dogs or cats, but not with rabbits or rats.

Acknowledgement : The present study was partically supported by the grant-in-aid from the Japanese Educational Ministry. Compound 6890-A was generously supplied by Smith Kline \& French Labs., McN-A-343 by McNeil Labs., Inc., P-286 by Pitman-Moore Co., and dimethylphenylpiperazinium by Parke, Davis \& Co.

\section{REFERENCES}

1) Boon, W.R. : J. Chem. Soc. 1947, I, 307 (1947)

2) Bargeton, D., Krumm-Heller, G., Salesse, J., Tricaud, M.-E., Eon, M. and Jousse, S. : Arch. int. Pharmacodyn. 101, 416 (1955)

3) Kanda, Z, Sekiya, A., Kito, T. And Iedokoro, S. : Folia pharmacol. japon. 54, 357 (1958)

4) KANDA, Z. AND SEKIYA, A. : Ibid. 56, 91§ (1960)

5) IEDOKORO, S. : Nagoya Igaku 82, 1166 (1960)

6) Luduena, E.P. And Long, J.P. : Arch. int. Pharmacodyn. 131, 178 (1961)

7) Kumagai, H., Yui, T., Ogawa, K. and Ohga, H. : Seitaino Kagaku 5, 132 (1953)

8) BEck, L. : Amer. J. Physiol. 201, 123 (1961)

9) Kumagai, H. : Jap. Heart J. 4, 462 (1963)

10) Asakawa, S. : Med. J. Shinshu Univ. (in press)

11) Imai, S., Murase, H., Takeda, K., OKada, M. And ShigeI, T. : Folia pharmacol. japon. 61, 11 § (1965)

12) Sakuma, A. : This Journal 14, 477 (1964)

13) Akabane, J., Nakanishi, S., Kohei, H., Asakawa, S., Matsumura, R., Ogata, H. and MiyaZAWA, T. : THIS JOURNAL (in press)

14) Gatgounis, J. And Har't, R. : J. Pharmacol. 144, 252 (1964) 